\title{
Who responds to postal questionnaires?
}

\author{
ANN CARTWRIGHT
}

From the Institute for Social Studies in Medical Care, 14 South Hill Park, Hampstead NW3 2SB

Postal questionnaires have been used in the epidemiological field to study the habits, practices, preferences, and attitudes of professionals, ${ }^{1-4}$ to follow up patients, ${ }^{5-7}$ and to identify individuals of certain ages or with particular problems or experiences for more intensive study. ${ }^{8-10}$ Rather less often have they been used to survey random samples of nonprofessional groups. One example of this last approach was a study of infant feeding by Martin and Monk. ${ }^{11}$ They obtained a response to their postal survey of recent mothers of $81 \%$, but pointed out that postal surveys usually obtain lower response rates than interview ones. And, of course, any response under $100 \%$ is a cause for some concern. The problem is that only rarely is there any information about the non-responders.

This paper presents information from two different sources about responders and non-responders to postal studies of women's experiences of childbearing. These data were collected during a study aimed at assessing the feasibility of monitoring maternity services by sending postal questionnaires to mothers some four months after the birth of their babies. In the first stage of the study, information from the mothers was compared with data extracted from hospital records. The same information from the records was available about the mothers who did not reply. Later stages were based on samples from birth registrations, and some data about the total sample were available from the non-confidential part of these forms. At all stages mothers were sent two reminders if they did not respond. The questionnaires were in the form of an A5 booklet, and for most questions mothers were asked to put a tick in the box next to the answer that applied to them.

\section{Information from hospital records}

\section{METHOD}

Postal questionnaires were sent to samples of 100 women who had given birth in November 1982 in each of three hospitals. The accompanying letter to the mothers made no reference to our access to hospital records, and when any mother inquired how we had obtained her name we explained truthfully, but somewhat misleadingly, that the names and addresses of mothers who have had babies are available on birth registration forms. ${ }^{12}$ Eighty of the 100 births at each hospital were selected at random, the other 20 from groups of particular interest to us. Data about the mothers, their previous obstetric history, and their recent pregnancy and delivery were abstracted from the records.

\section{OVERALL RESPONSE}

Overall response to the postal questionnaire was $74 \%$ and this did not differ between the random sample and the special interest groups, so for this paper they have been combined. The response rates were $82 \%, 71 \%$, and $70 \%$ at the three hospitals, a variation which is only significant* if the first hospital, which was outside London, is compared with the other two, one of which was in London and the other on the outskirts.

What differences did we expect? Other studies ${ }^{13}$ have shown that women underreport terminations of pregnancy at interview surveys, and this happened on this postal study too. So would women who had had a termination be less likely to respond? This did not seem to have happened as the response rate among those with a termination recorded in the notes was $74 \%$, the same as for all mothers. Other characteristics of their previous obstetric history-stillbirths, miscarriages, previous livebirths, previous complications (Caesarean sections, forceps or Ventouse or breech deliveries)-were also unrelated to response rates. Neither were there any significant differences in response rates with various tests and procedures carried out during pregnancy (ultrasound,

*In general, attention is not drawn to differences that might have occurred by chance five or more times in 100 .

Table 1 Response by stage at which first attended for antenatal care

\begin{tabular}{lll}
\hline $\begin{array}{l}\text { No. of weeks } \\
\text { pregnant }\end{array}$ & $\begin{array}{l}\text { Proportion } \\
\text { responding }\end{array}$ & $\begin{array}{l}\text { No. of mothers } \\
(=100 \%)\end{array}$ \\
\hline Less than 12 & $82 \%$ & 44 \\
12 less than 14 & $76 \%$ & 49 \\
14 less than 16 & $86 \%$ & 57 \\
16 less than 18 & $78 \%$ & 37 \\
18 less than 20 & $67 \%$ & 30 \\
20 or more & $64 \%$ & 72 \\
\hline
\end{tabular}


AFP, amniocentesis, oestriols, and CTGs) but those first attending for antenatal care relatively late in pregnancy were less likely to respond than those attending earlier. This is shown in table 1.

This relationship suggests that there may be a group of procrastinators who are late attenders for antenatal care and non-responders to surveys. But there was no difference in the response rate of those attending or not attending preparation classes. Another possible explanation is that those who had attended late had been alienated by people's reactions to this somewhat deviant behaviour. But if that had been the case, it might be expected that smokers would also be less likely to respond. This was not so.

Turning to their experiences of labour and delivery, response rates did not differ according to whether or not their labour was induced, whether they had an enema, a Caesarean section, an epidural, a forceps or Ventouse delivery, or by their length of stay in hospital. There was a puzzling difference with length of labour: a higher response among those whose second stage lasted 15 minutes or more $(78 \%)$ compared with $61 \%$ for those with a shorter second stage. Probably this is a chance effect. In examining 20 factors associated with maternity care, it is to be expected that there might be one or two statistically significant differences at the $5 \%$ level by chance.

The more understandable differences that emerged related to the baby. Mothers whose babies weighed less than $2500 \mathrm{~g}$ at birth, or whose baby stayed in hospital after the mother was discharged, were less likely to respond to the survey. The figures are given in table 2, which also shows a possible difference with the baby's admission to a special care baby unit but no significant differences after resuscitation or other problems recorded for the baby. There were also substantial differences over breast feeding: mothers who did not breast feed were less likely to respond as were mothers who were recorded as not intending to breast feed.

Looking at the demographic and descriptive data about the mothers recorded in the hospital notes, those who had never been in paid employment were less likely to respond than those who had worked or were working, $67 \%$ against $80 \%$, but differences according to social class (as measured by either the woman's or her partner's occupation), although in the expected direction with a higher response from those in non-manual jobs, did not reach the level of significance at even the $10 \%$ level. There was no trend in response rates with the mother's age.

Mothers who were described as 'white', 'Caucasian' or 'British' were more likely to respond than other groups, $79 \%$ compared with $60 \%$, and, associated? with this, those whose religion was recorded as 0 , Moslem were less likely to respond, $44 \%$ against $78 \% .0$ Hindu mothers had a response rate of $76 \%$, similar to 응 those described as Church of England, Roman $\vec{D}-\vec{D}$ Catholic, Non-conformist or Jewish, for whom it was $\mathbb{D}$ $78 \%$.

Further data relating response rates to social class and to factors associated with ethnic origin are presented in the next part of this paper.

Table 2 Variation in response with characteristics of baby

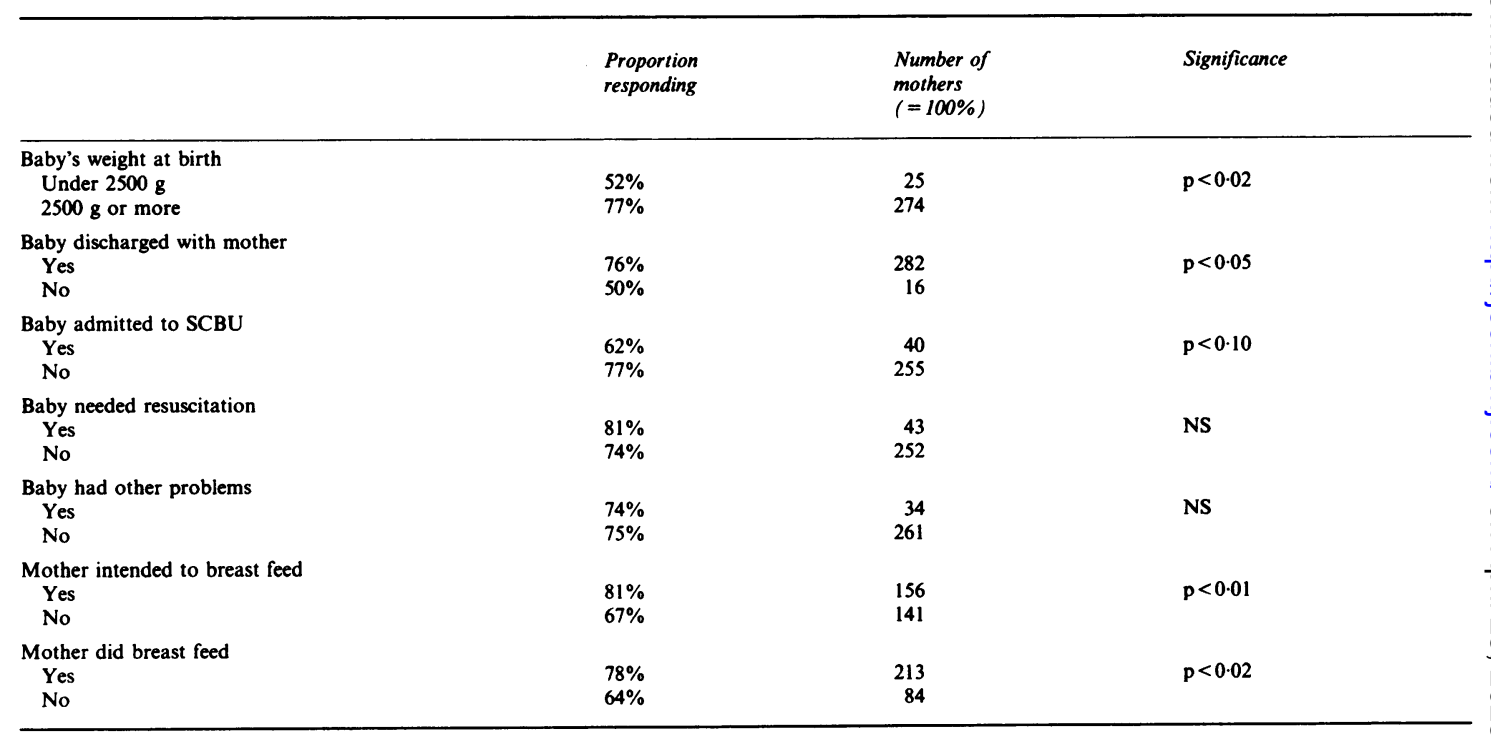


Information from birth registration forms

This part of the study was done in ten areas (registration districts or combinations of registration districts) in England. They were chosen systematically and with a random starting point, with probability proportional to the number of births in 1982. In each of these ten areas, OPCS selected a random sample of 160 births * registered in April 1984 and a further similar sample of 1600 registered in August 1984, a grand total of 3200 . Postal questionnaires were sent out to the first group in July 1984 and to the second in October that year. Two reminders were sent at threeweekly intervals to the non-responders.

\section{RESPONSE BY STUDY AREA}

The overall response to this part of the study was $79 \%$. This varied from $88 \%$ in Oxford to $67 \%$ in Solihull North (table 3). Some of this considerable variation will later be shown to be related to other factors associated with response.

"Strictly maternities, since multiple births had the same chance of being included as single births.

Table 3 Response rates in the different study areas

\begin{tabular}{lll}
\hline Registration district & Response rate & $\begin{array}{l}\text { Base numbers } \\
(=100 \%)\end{array}$ \\
\hline Oxford & $88 \%$ & 320 \\
Plymouth/Tavistock & $85 \%$ & 320 \\
Reading/Newbury & $83 \%$ & 320 \\
Derby, etc* & $83 \%$ & 320 \\
Leicestershire Central, etct & $81 \%$ & 320 \\
Durham, Eastern and Northern & $79 \%$ & 320 \\
Salford/Trafford & $77 \%$ & 320 \\
Havering and Redbridge & $75 \%$ & 320 \\
Huddersfield & $75 \%$ & 320 \\
Solihull North & $67 \%$ & 320 \\
All areas & $79 \%$ & 3200 \\
\hline
\end{tabular}

*Derby, Ashbourne, Belper \& Ripley, Ilkeston, Swadlincote

tLeicestershire Central, Coalville, Hinckley, Loughborough, Market Harborough, Melton Mowbray, Rutland

Table 4 Mother's country of birth and response rate

\begin{tabular}{lllr}
\hline Country of birth & $\begin{array}{l}\text { Proportion born } \\
\text { in different } \\
\text { countries } \\
\%\end{array}$ & \multicolumn{2}{c}{ Response rate } \\
\cline { 3 - 4 } & $\%$ & & No. \\
\hline UK & 86 & $83 \%$ & $2762 *$ \\
Eire & 1 & $73 \%$ & 33 \\
Other European & 1 & $87 \%$ & 40 \\
USA/Canada/Australia/New Zealand & 1 & $72 \% \dagger$ & 18 \\
Africa & 2 & $64 \%$ & 67 \\
Asia & 8 & $42 \%$ & 248 \\
Other & 1 & $81 \%$ & 32 \\
All countries & $3200(=100 \%)$ & $79 \%$ & 3200 \\
\hline
\end{tabular}

Numbers on which percentages are based $(=100 \%)$

tBased on less than 20 mothers
One of these is the mother's country of birth. The response rate for those born in the UK was $83 \%$. This did not differ significantly from the response by mothers born in Eire, in other European countries or in the USA, Canada, Australia or New Zealand. But the response rate was significantly lower among the small group of mothers born in Africa and substantially lower among the larger group born in Asia (table 4).

The baby's father's country of birth is also given on the birth registration forms and was associated with similar variations in response rates: $84 \%$ when the father was born in the UK, $45 \%$ when he was born in Asia, and $62 \%$ when he was born in Africa (no father was identified for $6 \%$ of the births). There was a strong association between the place of birth of the two parents. When the father was born in the UK, $96 \%$ of the mothers were born there too; when he was born in Asia so were $80 \%$ of the mothers, while $7 \%$ came from Africa and $13 \%$ had been born in the UK; and for babies whose fathers were born in Africa, $54 \%$ of their mothers were also born there, $19 \%$ in Asia and $25 \%$ in the UK.

Country of birth is, of course, related to ethnic origin. But some mothers with Asian or West Indian origins will have been born in the UK. Among the 68 who completed our questionnaire and described their ethnic origin as Asian, $63 \%$ had been born in Asia, $24 \%$ in Africa, and $12 \%$ in the UK (leaving $1 \%$ born elsewhere); while among the 19 who described themselves as West Indian, nearly half had been born in the UK.

For Asians, another indicator of ethnic origin that was on the birth registration form was their name. For the second half of our sample of birth registrations, mothers with an Asian name were identified by using a Directory of Ethnic Names from the Ethnic Statistics Unit of the Office of Population Censuses and Surveys and with help from the people in that unit. Nine per cent of all mothers were classified in this way: of these, $72 \%$ had been born in Asia, $15 \%$ in Africa, and $13 \%$ in the UK. Looking at this the other way, $86 \%$ of those born in Asia were identified as having an Asian name. The response rate among those with an Asian name was $43 \%$. Among those responding, all but one of those with an Asian name indicated that their ethnic origin was Asian; the other, who had been born in Pakistan, had indicated that she was African.

A key factor probably responsible for the associations between response rates and country of birth or having an Asian name is language. There is no information about this on the birth registration, and it was difficult to formulate an appropriate question about this on the questionnaire.

It might be expected that marital status would be related to response. This is not stated directly on the 
non-confidential part of the birth registration form, but for some births no father is identified and for others the mother and father have different surnames, and both of them registered the birth. Response rates in the three groups are shown in table 5.

Altogether $73 \%$ of the mothers assumed to be single replied compared with $81 \%$ of the married ones, but the main difference was between those for whom no father was identified and the others. The difference between those who were married and those unmarried mothers whose partner was recorded on the form was not significant.

Social class, as indicated by the occupation of the baby's father, was related to response rates, being higher for the middle class (in non-manual jobs) than for the working class (in manual jobs). But social class was also associated with the mother's country of birth. When the father's job was classified as non-manual, a comparatively small proportion of mothers had been born in Asia, 5\%, compared with $10 \%$ when the fathers were in manual occupations. However, taking mothers born in the UK only, the response was still clearly related, but not so strongly, to social class (table 6).

Delays in registering births tended to be greater among mothers born in Asia and Africa than among those born in the UK or elsewhere (table 7).

This difference between those born in Africa or Asia and the rest partly explains the clear trend between response rates and the interval between birth and registration shown in the final column of table 8 . If the

Table 5 Response and marital status

\begin{tabular}{lcc}
\hline & Response rate & Number of births $=100 \%$ \\
\hline No father identified & $69 \%$ & 203 \\
Mother \& father different surnames & $76 \%$ & 301 \\
\& both registered birth & & 2696 \\
Mother and father assumed married $81 \%$ &
\end{tabular}

Table 6 Social class and response rate

\begin{tabular}{|c|c|c|c|c|c|}
\hline \multicolumn{2}{|c|}{$\begin{array}{l}\text { Social class of father's } \\
\text { occupation }\end{array}$} & \multicolumn{4}{|c|}{ Response rate } \\
\hline & & \multicolumn{2}{|c|}{ Mothers born in UK only } & \multicolumn{2}{|c|}{ All mothers } \\
\hline & & & No & & No \\
\hline$\underset{\text { IIIN }}{\text { II }}$ & $\begin{array}{l}\text { Professional } \\
\text { Intermediate } \\
\text { Skilled non-manual }\end{array}$ & $\begin{array}{r}93 \% \\
89 \% 89 \% \\
86 \%\end{array}$ & $\begin{array}{l}150 \\
502 \\
284\end{array}$ & $\begin{array}{r}88 \% \\
86 \% 87 \% \\
84 \%\end{array}$ & $\begin{array}{l}187 \\
584 \\
319\end{array}$ \\
\hline \multirow[t]{3}{*}{$\underset{\text { IV }}{\text { IIIM }}$} & $\begin{array}{l}\text { Skilled manual } \\
\text { Partly skilled } \\
\text { Unskilled }\end{array}$ & $\begin{array}{r}84 \% \\
81 \% 76 \% \\
80 \%\end{array}$ & $\begin{array}{l}954 \\
343 \\
181\end{array}$ & $\begin{array}{r}80 \% \\
76 \% 69 \% \\
72 \%\end{array}$ & $\begin{array}{r}1074 \\
430 \\
213\end{array}$ \\
\hline & Armed forces & $89 \%$ & 76 & $89 \%$ & 79 \\
\hline & Other* & $78 \%$ & 87 & $73 \%$ & 111 \\
\hline
\end{tabular}

* Students, unemployed, and those for whom the job description was inadequate.
Table 7 Mother's country of birth and interval between birth and registration

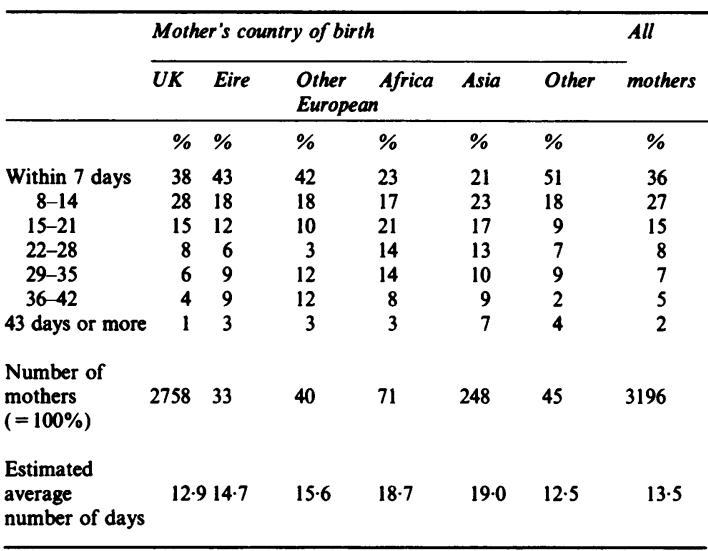

analysis is confined to mothers born within the UK the trend is less pronounced but is still significant.

Other data on the birth registration form related to the baby's sex and whether the birth was a single or $\stackrel{\mathscr{C}}{+} \dot{\omega}$ multiple one. There was a small but statistically significant difference in response rate according to the 0 baby's sex, $78 \%$ of those with a boy responding $\stackrel{\mathbb{\Phi}}{\circ}$ 을 compared with $81 \%$ of those with a girl. Although it is $\mathbb{\Omega} \vec{\varnothing}$ sometimes maintained that girls are easier to look $\mathbb{D}$ after, and this might mean that their mothers had more time and energy to take on additional tasks, no data too support this hypothesis have been located. By contrast, rather more of the mothers with twins $\frac{0}{2}$ replied, $90 \%$ against $79 \%$. Those with twins may have? been more eager to report their experiences, but the difference did not quite reach the $5 \%$ level of statistical significance.

How far do the differences in response by country of birth and social class account for the variations by area? Table 9 shows how the mother's country of birth varied in the ten study areas. Solihull North with the lowest response rate had the highest proportion of Asian mothers. But the bottom row of the table gives

Table 8 Response rate and interval between birth and registration

\begin{tabular}{|c|c|c|c|c|}
\hline \multirow{3}{*}{ Birth registered } & \multicolumn{4}{|c|}{ Response rate } \\
\hline & \multicolumn{2}{|c|}{ Mothers born in UK only } & \multicolumn{2}{|c|}{ All mothers } \\
\hline & & No & & No \\
\hline $\begin{array}{l}\text { Within } 7 \text { days } \\
8-14 \text { days } \\
15-21 \text { days } \\
22-28 \text { days } \\
29-35 \text { days } \\
36-42 \text { days } \\
43 \text { days or longer }\end{array}$ & $\begin{array}{l}85 \% \\
85 \% \\
82 \% \\
80 \% \\
81 \% \\
74 \% \\
82 \%\end{array}$ & $\begin{array}{r}1041 \\
784 \\
401 \\
209 \\
171 \\
118 \\
34\end{array}$ & $\begin{array}{l}83 \% \\
81 \% \\
78 \% \\
73 \% \\
76 \% \\
71 \% \\
59 \%\end{array}$ & $\begin{array}{r}1163 \\
875 \\
471 \\
257 \\
218 \\
156 \\
56\end{array}$ \\
\hline
\end{tabular}


the response rates in the different areas for mothers born in the UK. This varied less than the total response rate, but Solihull still had the lowest rate. Clearly, variations in the proportion coming from different countries does not account for all the differences between areas.

Social class also varies between areas, and table 10 shows how it does so for mothers born in the UK. The

Table 9 Area by response rate and mother's country of birth

\begin{tabular}{|c|c|c|c|c|c|c|c|c|c|c|c|}
\hline & 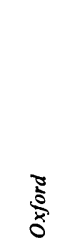 & 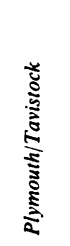 & 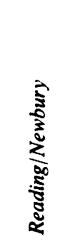 & $\begin{array}{l}\vdots \\
\vdots \\
\vdots \\
\vdots\end{array}$ & 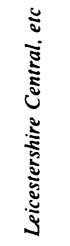 & $\underset{\frac{5}{5}}{\mathrm{~s}}$ & 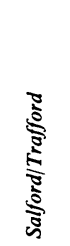 & 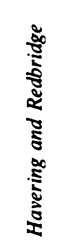 & 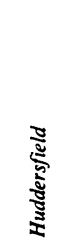 & 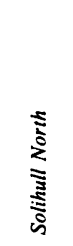 & $\begin{array}{l}\frac{2}{5} \\
\frac{3}{7}\end{array}$ \\
\hline Response rate & $88 \%$ & $85 \%$ & $83 \%$ & $83 \%$ & $81 \%$ & $79 \%$ & $77 \%$ & $75 \%$ & $75 \%$ & $67 \%$ & $79 \%$ \\
\hline $\begin{array}{l}\text { Mother's country } \\
\text { of birth: }\end{array}$ & $\%$ & $\%$ & $\%$ & $\%$ & $\%$ & $\%$ & $\%$ & $\%$ & $\%$ & $\%$ & $\%$ \\
\hline UK & 89 & 97 & 86 & 88 & 78 & 97 & 93 & 82 & 81 & 73 & 86 \\
\hline Asian & 4 & 1 & 5 & 8 & 10 & 1 & 3 & 9 & 14 & 23 & 8 \\
\hline Africa & 1 & - & 3 & 2 & 9 & - & - & 5 & 1 & 2 & 2 \\
\hline Other & 6 & 2 & 6 & 2 & 3 & 2 & 4 & 4 & 4 & 2 & 4 \\
\hline $\begin{array}{l}\text { Number of births } \\
(=100 \%)\end{array}$ & 320 & 320 & 320 & 320 & 320 & 320 & 320 & 320 & 320 & 320 & 3200 \\
\hline $\begin{array}{l}\text { Response rate for } \\
\text { mothers born in } \\
\text { UK only }\end{array}$ & $\begin{array}{l}89 \% \\
284\end{array}$ & $\begin{array}{l}85 \% \\
310\end{array}$ & $\begin{array}{l}85 \% \\
276\end{array}$ & $\begin{array}{l}87 \% \\
283\end{array}$ & $\begin{array}{l}86 \% \\
249\end{array}$ & $\begin{array}{l}79 \% \\
310\end{array}$ & $\begin{array}{l}80 \% \\
296\end{array}$ & $\begin{array}{l}81 \% \\
263\end{array}$ & $\begin{array}{l}82 \% \\
259\end{array}$ & $\begin{array}{l}76 \% \\
232\end{array}$ & $\begin{array}{l}83 \% \\
2762\end{array}$ \\
\hline
\end{tabular}

Table 10 Area by response rate and social class for mothers born in the UK only

\begin{tabular}{|c|c|c|c|c|c|c|c|c|c|c|c|}
\hline & కై & $\begin{array}{l}\stackrel{\vdots}{0} \\
\grave{a} \\
\stackrel{0}{0}\end{array}$ & 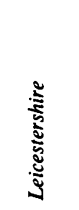 & 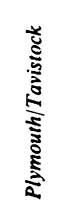 & 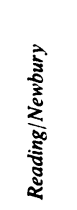 & 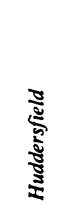 & 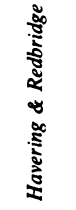 & 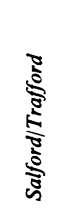 & 苞 & ڤ్ & 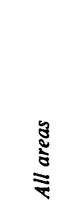 \\
\hline $\begin{array}{l}\text { Response rate for } \\
\text { mothers born in } \\
\text { UK only }\end{array}$ & $89 \%$ & $87 \%$ & $86 \%$ & $85 \%$ & $85 \%$ & $82 \%$ & $81 \%$ & $80 \%$ & $79 \%$ & $76 \%$ & $83 \%$ \\
\hline \multicolumn{12}{|l|}{ Social class of father's } \\
\hline I & 12 & 5 & 2 & 6 & 12 & 6 & 8 & 5 & 3 & 3 & 6 \\
\hline II & 32 & 18 & 19 & 19 & 32 & 27 & 26 & 15 & 10 & 8 & 21 \\
\hline IIIN & 14 & 12 & 12 & 8 & 8 & 13 & 19 & 13 & 9 & 9 & 12 \\
\hline IIIM & 28 & 41 & 48 & 40 & 36 & 41 & 34 & 40 & 43 & 44 & 39 \\
\hline IV & 8 & 16 & 15 & 15 & 8 & 8 & 11 & 19 & 20 & 24 & 14 \\
\hline v & 6 & 8 & 4 & 12 & 4 & 5 & 2 & 8 & 15 & 12 & 8 \\
\hline$\%$ Non-manual & $58 \%$ & $35 \%$ & $33 \%$ & $33 \%$ & $52 \%$ & $46 \%$ & $53 \%$ & $33 \%$ & $22 \%$ & $20 \%$ & $39 \%$ \\
\hline $\begin{array}{l}\text { Number of mothers } \\
(=100 \%)\end{array}$ & 251 & 262 & 222 & 232 & 248 & 232 & 249 & 246 & 281 & 182 & 2405 \\
\hline $\begin{array}{l}\text { Response rate among non- } \\
\text { manual group }\end{array}$ & $\begin{array}{l}92 \% \\
146\end{array}$ & $\begin{array}{l}92 \% \\
93\end{array}$ & $\begin{array}{l}91 \% \\
74\end{array}$ & $\begin{array}{l}80 \% \\
76\end{array}$ & $\begin{array}{l}93 \% \\
129\end{array}$ & $\begin{array}{l}87 \% \\
106\end{array}$ & $\begin{array}{l}87 \% \\
132\end{array}$ & $\begin{array}{l}88 \% \\
83\end{array}$ & $\begin{array}{l}92 \% \\
61\end{array}$ & $\begin{array}{l}75 \% \\
36\end{array}$ & $\begin{array}{l}89 \% \\
936\end{array}$ \\
\hline $\begin{array}{l}\text { Response rate among } \\
\text { manual group }\end{array}$ & $\begin{array}{l}87 \% \\
105\end{array}$ & $\begin{array}{l}85 \% \\
169\end{array}$ & $\begin{array}{l}89 \% \\
148\end{array}$ & $\begin{array}{l}88 \% \\
156\end{array}$ & $\begin{array}{l}78 \% \\
119\end{array}$ & $\begin{array}{l}79 \% \\
126\end{array}$ & $\begin{array}{l}76 \% \\
117\end{array}$ & $\begin{array}{l}79 \% \\
163\end{array}$ & $\begin{array}{l}75 \% \\
220\end{array}$ & $\begin{array}{l}82 \% \\
146\end{array}$ & $\begin{array}{l}81 \% \\
1469\end{array}$ \\
\hline
\end{tabular}


areas are listed in order of the response rate for this group of mothers. Oxford has the highest response and the highest proportion of fathers in non-manual jobs, whereas Durham and Solihull North are at the bottom end of both these scales. In between the agreement is less good.

The bottom part of the table shows the response rates for the different areas separately for the middle (non-manual occupations) and working (manual occupations) classes - still just for mothers born in the UK. Variation between areas for both groups was still greater than would be expected by chance, but there was no correlation between the two series.

In short, variations in mother's country of birth and in social class explain some but not all the wide differences in response rates between areas.

\section{Summary and discussion}

Comparisons of respondents and non-respondents in relation to data from hospital records were generally encouraging in that there was no indication of a bias associated with women's ages, smoking habits, previous obstetric history, including terminations, or tests and procedures that were carried out during pregnancy, labour, and delivery. The most notable bias that emerged related to the baby's health, with a low response from mothers of low birth weight babies, babies that were kept in after the mother was discharged, and babies admitted to special care baby units-three related events. Some of these babies may not have survived, and it is not surprising if their mothers were reluctant to respond to a postal questionnaire about events that they may now be anxious to forget and may now view with sadness and possibly anger or guilt. In an interview study of a random sample of live and still births ${ }^{14}$ the response rate was higher among mothers who had a live birth, $91 \%$, than among those who had a still birth, $82 \%$.

Other significant biases related to breast feeding and to late attendance at antenatal clinic. This last finding ties in with one from the second part of this paper showing that delay in registering the birth was associated with a relatively poor response. This suggests that there may be a group of mothers who tend to postpone or put off attending for antenatal care, registering the birth, and completing questionnaires.

Data from hospital records showed a somewhat lower than average response from mothers not described as "white", "Caucasian" or "British" and a much lower response for those whose religion was Moslem. The fact that the response from the Hindu mothers in that part of the study was good may reflect the period of establishment of particular immigrant groups attending the three study hospitals. In the larger and more representative sample from birth registrations, the response was very low from mothers born in Asia or from those with an Asian name and was relatively low among those born in Africa. Since many of these mothers may not read or write English, and quite a lot may not speak it, there is no easy solution to this problem. An approach by interview might help some, but others would need interpreters, which is often not a very satisfactory solution, and some would probably be unwilling to cooperate. In an interview study based on a basically similar but earlier sample of live births ${ }^{14}$ response rates varied significantly with the mother's country of birth. They were $92 \%$ among mothers born in England, Wales or Scotland compared with $81 \%$ for those born in India, Pakistan or Bangledesh (additional unpublished data).

Social class showed significant differences with response in the second part of this study-the differences in the first part being in the same direction but not reaching significance. The difference was reduced, but not eliminated, when analysis waş confined to women born in the UK. This bias towards a group who are better off and better educated is probably an inevitable hazard of postal surveys. In the earlier interview study the overall response rate of $91 \%$ did not vary significantly with social class, but more recently on a study in four areas a highero response from middle-class than from working classe mothers was found on the interview as well as on the postal study. The response rates were $96 \%$ from middle-class mothers and $90 \%$ from working class mothers to the interview compared with $78 \%$ and $74 \%$ respectively to the postal study.

So the main biases in response, relating to ethnic origin, social class, and the baby's health, may not be avoided by an interview as opposed to a postal survey. However, there will be substantial savings in cost if a postal approach is used. Sampling, clerical, administrative, and coding costs are roughly similar but interviewing and travelling costs are likely to be at least 20 , and probably nearer 50 , times greater than the postage.

This study was made possible by the mothers who answered our questions, the hospital staff who gave us access to their records, OPCS who selected the sample of birth registration, and the Medical Research Council who funded it. I am also indebted to my colleagues, particularly Claudia Martin, Ann Jacoby, and Danny Kushlick, but also Robert Anderson, Heather Taylor, Polly Wilson, and others and to the Institute's Advisory Committee. 


\section{References}

${ }^{1}$ Doll Richard, Hill A Bradford. The mortality of doctors in relation to their smoking habits: a preliminary report. $\mathrm{Br}$ Med J 19541 1451-55.

2 Waite Marjorie Health visitors and birth control advice 1970/71. Nursing Times 1972 October 12/19.

${ }^{3}$ Parkhouse J, Palmer MK. Career preferences of doctors qualifying in 1975. Br Med J 19772 25-7

${ }^{4}$ Haines Andrew, Booroff Angela Terminal care at home: perspective from general practice. Br Med J 1986292 $1051-3$.

${ }^{5}$ Lowdon AGR, Stewart RHM, Walker W. Risk of serious infection following splenectomy $\mathrm{Br}$ Med J 19661 446-50.

${ }^{6}$ Oxtoby Marie Parkinson's disease patients and their social needs London: Parkinson's Disease Society. 1982.

${ }^{7}$ Kaufert Patricia Leyland, and Kaufert Joseph $\mathbf{M}$. Methodological and conceptual issues in measuring the long term impact of disability: the experience of poliomyelitis patients in Manitoba Social Science and Medicine $198419609-18$
${ }^{8}$ Cartwright Ann Human relations and hospital care. London: Routledge and Kegan Paul. 1964.

${ }^{9}$ Harris Amelia I. Handicapped and impaired in Great Britain Part 1 London: HMSO. 1971.

${ }^{10}$ Farrell Christine My mother said . . . London: Routledge and Kegan Paul. 1978.

11 Martin Jean, Monk Janet Infant feeding 1980 London: OPCS Social Survey Division. 1982.

12 Cartwright Ann, Anderson Robert, Martin Claudia J. On the frontiers of ethics: issues confronted in two studies by the Institute for Social Studies in Medical Care. Social Science and Medicine, In press.

13 Dunnell Karen Family formation 1976 London: HMSO. 1979.

14 Cartwright Ann The dignity of labour? London: Tavistock. 1979. 